Article

\title{
Association of Occupational Noise Exposure and Incidence of Metabolic Syndrome in a Retrospective Cohort Study
}

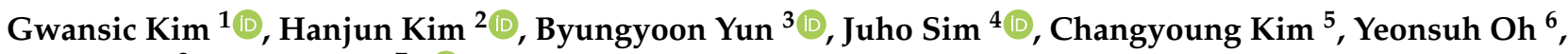 \\ Jinha Yoon ${ }^{3}$ and Jiho Lee ${ }^{7, * \mathbb{C}}$
}

1 Department of Thoracic and Cardiovascular Surgery, Ulsan University Hospital, Ulsan 44033, Korea; 0734519@uuh.ulsan.kr

2 Department of Occupational \& Environmental Medicine, Ulsan University Hospital, Ulsan 44033, Korea 0734979@uuh.ulsan.kr

3 Department of Preventive Medicine, Yonsei University College of Medicine, Seoul 03722, Korea; yby3721@yuhs.ac (B.Y.); flyinyou@yuhs.ac (J.Y.)

4 Department of Public Health, Graduate School, Yonsei University, Seoul 03722, Korea; yodasim@yuhs.ac

5 Big Data Center, Ulsan University Hospital, Ulsan 44033, Korea; fingertree@uuh.ulsan.kr

6 Environmental Health Center, University of Ulsan College of Medicine, Ulsan 44033, Korea; s2lovesky00@naver.com

7 Department of Occupational \& Environmental Medicine, University of Ulsan College of Medicine, Ulsan 44033, Korea

* Correspondence: oemdoc@naver.com; Tel.: +82-52-250-7288; Fax: +82-52-250-7288

check for

updates

Citation: Kim, G.; Kim, H.; Yun, B.; Sim, J.; Kim, C.; Oh, Y.; Yoon, J.; Lee, J. Association of Occupational Noise Exposure and Incidence of Metabolic Syndrome in a Retrospective Cohort Study. Int. J. Environ. Res. Public Health 2022, 19, 2209. https:// doi.org/10.3390/ijerph19042209 Academic Editors: Ivo Iavicoli and Veruscka Leso

Received: 21 December 2021

Accepted: 8 February 2022

Published: 15 February 2022

Publisher's Note: MDPI stays neutral with regard to jurisdictional claims in published maps and institutional affiliations.

Copyright: (C) 2022 by the authors. Licensee MDPI, Basel, Switzerland. This article is an open access article distributed under the terms and conditions of the Creative Commons Attribution (CC BY) license (https:// creativecommons.org/licenses/by/ $4.0 /)$.

\begin{abstract}
Metabolic syndrome is one of the common causes of cardiovascular diseases and cancers Although noise is an environmental factor to which people can be commonly exposed at work and in daily life, there are currently insufficient studies on the relationship between noise and metabolic syndrome. Therefore, the purpose of this study is to investigate the relationship between noise and metabolic syndrome. Using a multivariate time-dependent Cox proportional hazard model, the impacts of occupational noise exposure on metabolic syndrome and its components were analyzed in a retrospective cohort of 60,727 participants from 2014 to 2017 . The noise exposure group showed a significantly higher incidence of metabolic syndrome and was associated with elevated triglycerides, blood sugar, and blood pressure, but decreased high-density lipoprotein, among subgroups. There was no statistically significant association with abdominal obesity. Occupational noise exposure significantly contributed to the incidence of metabolic syndrome and changes in its components. This study could be a basis for establishing policies and guidelines to reduce noise exposure that might improve workers' health.
\end{abstract}

Keywords: metabolic syndrome; occupational noise; cohort study; workers' health examination

\section{Introduction}

Although metabolic syndrome is defined differently for each organization, it is generally defined as a coexistence of conditions that can cause cardiovascular disease, such as insulin resistance, hypertension, and dyslipidemia. According to the definition (1998) by the World Health Organization (WHO) [1], metabolic syndrome is the co-existence of at least one of diabetes mellitus, impaired glucose tolerance, low fasting blood sugar, and insulin resistance and two or more of the symptoms of hypertension, dyslipidemia, central obesity, and microproteinuria. In addition, the European Group for the Study of Insulin Resistance (EGIR), National Cholesterol Education Program Adult Treatment Panel III (NCEP ATP III), and International Diabetes Federation (IDF) organizations also have standards for metabolic syndrome, and it is suggested that it is reasonable to use the standard proposed by 2005 NCEP ATP III criteria according to the racial standard for each country [2] (Table A1). 
The prevalence of metabolic syndrome varies from country to country and is increasing in some developing countries [3], but in the United States, abdominal obesity has increased, while dyslipidemia and impaired glucose tolerance have decreased, keeping the prevalence of total metabolic syndrome constant [4]. In Korea, there was a significant increase from 1998 to 2007, but, similar to the trend in the United States, it did not change significantly until 2017. However, it seems that there is a large difference depending on lifestyle factors, as, for example, the trend of prevalence between men and women is different, and the trend of the prevalence of each diagnostic criterion is also different [5].

Metabolic syndrome, as shown in its definition and diagnostic criteria, is highly correlated with cardiovascular disease and diabetes, and this can lead to increased mortality [6]. In addition, metabolic syndrome can be a risk factor for not only cerebrovascular disease, but also neurological diseases such as Alzheimer's and depression [7], and lung diseases such as asthma and pulmonary hypertension [8].

As there are various diagnostic criteria for metabolic syndrome, there are also multiple causative factors. First, there is westernized lifestyle. Higher caloric intake and reduced physical activity increase the risk for all factors of metabolic syndrome, and excessive calorie intake can increase the severity [9]. Genetic factors, [10], the living and working environments, and exposure to various drugs and environmental pollutants can predispose to the onset of metabolic syndrome [6]. In this manner, metabolic syndrome can result from complex interaction of various factors, and chronic exposure to diverse risk factors rather than a single event or a certain risk factor. Therefore, in order to prevent metabolic syndrome, exposure to all possible risk factors should be reduced, and thus a multifaceted approach and understanding are required.

As it is thought that various work environmental factors are related to the occurrence of metabolic syndrome and that a lot of time is spent during the day in general in the workplace, it is necessary to study the relationship between the workplace and metabolic syndrome. One of the major chronical influencing factors of the workplace environment is noise exposure. There are studies on noise exposure and metabolic syndrome from some countries [11,12], but there are still many unknowns, including the causal relationship. Furthermore, from previous studies on the association between noise exposure and components of the diagnostic criteria for metabolic syndrome, there is a correlation between the increase in diabetes incidence and noise exposure, and prolonged noise exposure is a risk factor for insulin resistance. Additionally, prior research proposed several mechanisms of noise effect on metabolic syndrome in aspects of the central nervous system, endocrine system, and psychological stressors $[13,14]$. In addition, noise exposure at work increases the risk of hypertension [15] and is considered to be one of the risk factors for obesity [16].

This study aimed to investigate the impact of occupational noise exposure on the incidence of metabolic syndrome and on each component using a cohort dataset of workers. This study would be a motivation for polices on noise reduction in the workplace.

\section{Materials and Methods}

\subsection{Data Source and Subjects}

This is a retrospective cohort study using health examination data. Overall, 60,727 workers at a shipbuilding industry in Ulsan who received a workers' health examination at Ulsan University Hospital in 2014 were selected as a research sample and observed until 2017. To evaluate the effect of noise exposure on metabolic syndrome, among a sample of 60,727 workers, there were excluded 27,162 workers who had been previously exposed to noise, 7408 workers who had already been diagnosed with metabolic syndrome, 6977 workers who failed to follow-up, and 299 workers who were diagnosed with metabolic syndrome within 1 year after the start of the study. Finally, 18,881 study subjects were selected. Among them, the noise-exposed group ( $n=2693$ subjects) and the non-noise-exposed group ( $n=16,188$ subjects) were divided and analyzed for comparison. (Figure 1). 
60,727 participants who took baseline health examination in 2014

Excluded

27,162 Exposed to noise previously

7408 Previously diagnosed with metabolic syndrome

6977 Participants who were not followed up after baseline

299 Participants diagnosed with metabolic syndrome within 1 year

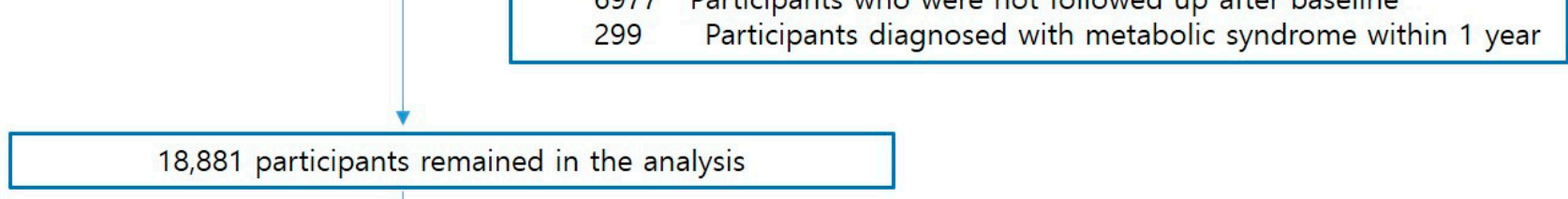

2693 Noise exposure

16,188 Non-exposure

Figure 1. Flowchart of study subject selection to analyze effect of noise exposure on metabolic syndrome.

In addition, in order to investigate the incidence rates of subgroups of metabolic syndrome according to noise exposure, subjects whose parameters exceeded the diagnostic criteria for each of the five sub-items of metabolic syndrome were excluded. Finally, 21,233 subjects with abdominal obesity, 10,834 subjects with elevated blood pressure, 15,113 subjects with elevated triglycerides (TG), 19,234 subjects with decreased high-density lipoprotein cholesterol (HDL-C), and 13,269 subjects with elevated blood sugar were selected as study subjects, respectively. The noise-exposed group and the non-noiseexposed group were divided and analyzed for comparison. (Figure A1).

This study was reviewed and approved by the Ulsan University Hospital Institutional Review Board (UUH IRB) (IRB No: 2021-06-042-001).

\subsection{Covariate Definition and Measurement}

The subjects of this study received regular health examination every year in Ulsan, and the following items were collected from these data. Baseline demographic characteristics included age, sex, height, weight, body mass index (BMI), waist circumference, systolic blood pressure, diastolic blood pressure, smoking history, drinking history, physical activity, presence or absence of exposure to cardiovascular-related risk factors, exposure to noise, presence or absence of underlying diseases (hypertension, diabetes, and dyslipidemia) and related medication history, fasting plasma glucose level, TG level, and HDL-C levels.

Noise exposure levels at the workplace were measured with a sound meter that complies with the requirements of the American National Standards Institute. The National Institute for Occupational Safety and Health (NIOSH) reported that a time-weighted averaged recommended exposure limitation (REL) should be $85 \mathrm{dBA}$ for $8 \mathrm{~h}$ to minimize the harmful effects of noise exposure [17], and the American Conference of Governmental Industrial Hygienists also recommended the same standard ( $85 \mathrm{dBA}$ ) [18]. Therefore, in this study subjects exposed to noise exceeding $85 \mathrm{dBA}$ in the 8-hour time-weighted average at the workplace during the follow-up period were classified into the noise-exposure group, and the rest were classified into the non-noise-exposure group.

Height $(\mathrm{cm})$ and weight $(\mathrm{kg})$ were measured using an automatic height weigher (GL150 R, G Tech international, South Korea), and body mass index (BMI) was measured by weight $(\mathrm{kg})$ divided by the square of height $(\mathrm{m})$. According to the criteria presented by the Korean Society for the Study of Obesity [19], underweight $(<18.5)$, normal weight (18.5-22.9), overweight (23-24.9) and obese $(\geq 25)$ were classified by four stages depending on BMI. Waist circumference was measured using a tape measure at the midpoint between the highest position of the pelvis (iliac crest) and the midpoint of the lowest rib, with 
both feet slightly shoulder-width apart and standing in an upright position, exhaling comfortably. Blood pressure was measured using an automatic sphygmomanometer (FT500 R PLUS, JAWON MEDICAL, South Korea) in a sitting position after resting for at least $10 \mathrm{~min}$. Smoking history was classified into three groups (non-smokers, former smokers, and current smokers) according to the smoking status. Non-smokers were defined as those who had smoked fewer than 5 packs of cigarettes in their lifetime. Those who had stopped smoking were classified as ex-smokers, and those who continued to smoke were classified as current smokers. Drinking history was defined as having a drinking habit with an average of 7 or more drinks per day for men and 5 or more drinks for women at least twice a week regardless of the type of alcohol consumed [20]. Physical activity was classified into an exercise group when moderate or vigorous physical activity was performed more than twice a week, and the rest were classified into a non-exercise group. Vigorous physical activity ( $>6$ METs) was strenuous activity that made the subject to be out of breath much more than usual (e.g., heavy lifting, digging, aerobics, or fast bicycling, etc.). Moderate physical activity (3-6 METs) was activity that made the subject to be a little bit more out of breath than usual, such as biking at a moderate pace and doubles tennis [21].

Cardiovascular-related risk factors included carbon monoxide, nitric dioxide, cyanide compounds, antimony compounds, carbon disulfide, trichlorethylene, ethylene glycol dinitrate, acetonitrile, methyl chloroform, freon 21 (dichlorofluoromethane), methylene chloride (dichloromethane), nitroglycerin, vibration, high pressure, low pressure, and exposure to night shift. This is in accordance with the Occupational Safety and Health Act of Korea. The presence or absence of cardiovascular-related risk factors was used as a covariate in the Cox proportional hazard model. All subjects fasted for at least 8 hours before undergoing the annual health examination, and then intravenous blood sampling was performed to measure fasting plasma glucose, TG, and HDL-C levels.

\subsection{Statistical Analysis}

The general characteristics of the study subjects were expressed as mean \pm standard deviation for continuous variables and frequency (\%) for categorical variables. Continuous variables were compared by Student's t-test, and categorical variables were compared by chi-square test. When studying data that have already been established over a long period of time, such as large-scale screening data, there is an immortal time bias, in other words, a guarantee-time bias, as a convenience to consider. To control this guarantee-time bias, a time-dependent Cox model and landmark analysis were performed. In the timedependent Cox proportional risk model, the dependent variable was the occurrence of metabolic syndrome or its components, and the exposure factor was noise exposure. Sex, age, smoking history, alcohol history, physical activity level, night-shift work, and exposure to cardiovascular-related risk factors were used as the covariates. Adjusted relative hazard ratios at 95\% confidence intervals were calculated using a multivariate time-dependent Cox proportional hazards model. The incidence of metabolic syndrome and 5 subgroups was marked as "event", and the cumulative incidence rates of metabolic syndrome and five subgroups according to noise exposure were compared and analyzed using Kaplan-Meier plots, respectively. In this study, when analyzing landmarks, the landmark time was set as a time point one year after the cohort entry. All hypothesis tests were performed as a two-tailed test, and a $p$ value $<0.05$ was interpreted as significant. $\mathrm{R}$ software version 4.0.2 (R Foundation for Statistical Computing, Vienna, Austria; www.r-project.org, accessed on 7 January 2022) was used for all statistical analysis.

\section{Results}

3.1. Association between Noise Exposure and Metabolic Syndrome

\subsubsection{Basic Demographic Characteristics}

In order to analyze the effect of noise exposure on metabolic syndrome, 18,881 subjects were finally selected from a study sample of 60,727 subjects. The basic demographic characteristics of the subjects of this study are described in Table 1. 
Table 1. Baseline characteristics of study groups for metabolic syndrome.

\begin{tabular}{|c|c|c|c|c|}
\hline Characteristics & $\begin{array}{l}\text { Total, No. }(\%) \\
(n=18,881)\end{array}$ & $\begin{array}{c}\text { Non-Exposure } \\
(n=16,188)\end{array}$ & $\begin{array}{l}\text { Noise Exposure } \\
\quad(n=2693)\end{array}$ & $p$-Value \\
\hline Age (year), mean (SD) & $41.04(11.06)$ & $41.27(11.06)$ & $39.66(1.97)$ & $<0.001$ \\
\hline \multicolumn{5}{|l|}{ Age (year) } \\
\hline$<30$ & $3369(17.8)$ & $2758(17.0)$ & $611(22.7)$ & \multirow{4}{*}{$<0.001$} \\
\hline $30-39$ & $5987(31.7)$ & $5174(32.0)$ & $813(30.2)$ & \\
\hline $40-49$ & $4544(24.1)$ & $3895(24.1)$ & $649(24.1)$ & \\
\hline$\geq 50$ & $4981(26.4)$ & $4361(26.9)$ & $620(23.0)$ & \\
\hline \multicolumn{5}{|l|}{ Gender } \\
\hline Male & $13,830(73.2)$ & $11,280(69.7)$ & $2550(94.7)$ & \multirow[t]{2}{*}{$<0.001$} \\
\hline Female & $5051(26.8)$ & $4908(30.3)$ & $143(5.3)$ & \\
\hline \multicolumn{5}{|l|}{ Body mass index, $\mathrm{kg} / \mathrm{m}^{2}$} \\
\hline Normal,18.5-22.9 & $8726(46.2)$ & $7498(46.3)$ & $1228(45.6)$ & \multirow{4}{*}{$<0.001$} \\
\hline Underweight, $<18.5$ & $589(3.1)$ & $550(3.4)$ & $39(1.4)$ & \\
\hline Overweight, 23-24.9 & $5333(28.3)$ & $4564(28.2)$ & $769(28.6)$ & \\
\hline Obese, $\geq 25$ & $4233(22.4)$ & $3576(22.1)$ & $657(24.4)$ & \\
\hline \multicolumn{5}{|l|}{ Smoking status } \\
\hline Non-smoker & $9792(51.9)$ & $8972(55.4)$ & $820(30.5)$ & \multirow{3}{*}{$<0.001$} \\
\hline Ex-smoker & 4091 (21.6) & $3566(22.0)$ & $525(19.5)$ & \\
\hline Current smoker & $4998(26.5)$ & $3650(22.6)$ & $1348(50.0)$ & \\
\hline \multicolumn{5}{|l|}{ Alcohol habit status } \\
\hline No & $10,581(56.0)$ & $9372(57.9)$ & $1209(44.9)$ & \multirow[t]{2}{*}{$<0.001$} \\
\hline Yes & $8300(44.0)$ & $6816(42.1)$ & $1484(55.1)$ & \\
\hline \multicolumn{5}{|l|}{ Physical activity } \\
\hline Non-exercise group & $2550(13.5)$ & $2105(13.0)$ & $445(16.5)$ & \multirow[t]{2}{*}{$<0.001$} \\
\hline Exercise group & $16,331(86.5)$ & $14,083(87.0)$ & $2248(83.5)$ & \\
\hline \multicolumn{5}{|l|}{ Night-shift work } \\
\hline No & $17,232(92.3)$ & $15,036(92.9)$ & $2196(81.5)$ & \multirow[t]{2}{*}{$<0.001$} \\
\hline Yes & $1649(8.7)$ & $1152(7.1)$ & $497(18.5)$ & \\
\hline \multicolumn{5}{|l|}{$\begin{array}{c}\text { Cardiovascular-related } \\
\text { exposure }\end{array}$} \\
\hline No & $17,377(92.0)$ & $15,928(98.4)$ & 1449 (53.8) & \multirow{2}{*}{$<0.001$} \\
\hline Yes & $1504(8.0)$ & $260(1.6)$ & $1244(46.2)$ & \\
\hline
\end{tabular}

The average age of the subjects was 41 years old, $17.8 \%$ were under $30,31.7 \%$ were in their $30 \mathrm{~s}, 24.1 \%$ were in their $40 \mathrm{~s}$, and $26.4 \%$ were in their $50 \mathrm{~s}$. Men accounted for $73.2 \%$, and body mass index showed a distribution of $28.3 \%$ and $22.4 \%$ for overweight and obesity, respectively. Non-smokers were $51.9 \%$, and $56 \%$ were in the non-drinking-habit group. The degree of physical activity was mostly moderately intense (86.5\%). Night-shift work experience was found in $8.7 \%$, and exposure to cardiovascular risk factors was found in $8.0 \%$. Of the total 18,881 subjects, $2693(14.3 \%)$ were exposed to noise, and $16,188(85.7 \%)$ were in the non-noise-exposed group. Compared with the non-noise-exposure group, the noise-exposure group had a younger average age of 39.66 years, and the proportion of women was lower at $5.3 \%$. In the noise-exposure group, there were more current smokers $(50 \%)$, more night-work experience $(18.5 \%)$, and much more exposure to cardiovascular risk factors $(46.2 \%)$. (Table 1$)$.

\subsubsection{Prevalence and Incidence of Metabolic Syndrome}

Among the study sample of 60,727 , the prevalence of metabolic syndrome was $12.2 \%$ (7408 patients) at onset, and at an average follow-up period of 2.39 years, the number of newly developed metabolic syndrome subjects was 997 out of 18,881 subjects, showing an incidence rate of $5.3 \%$. The comparison of the incidence rates of metabolic syndrome between the noise- and non-noise-exposure groups was statistically significant with higher incidence among the noise-exposure group $(6.6 \%, 177 / 2693 ; 5.1 \%, 820 / 16,188$, respectively, $p<0.001$ ) (Figure 2). 
Metabolic syndrome incidence rate

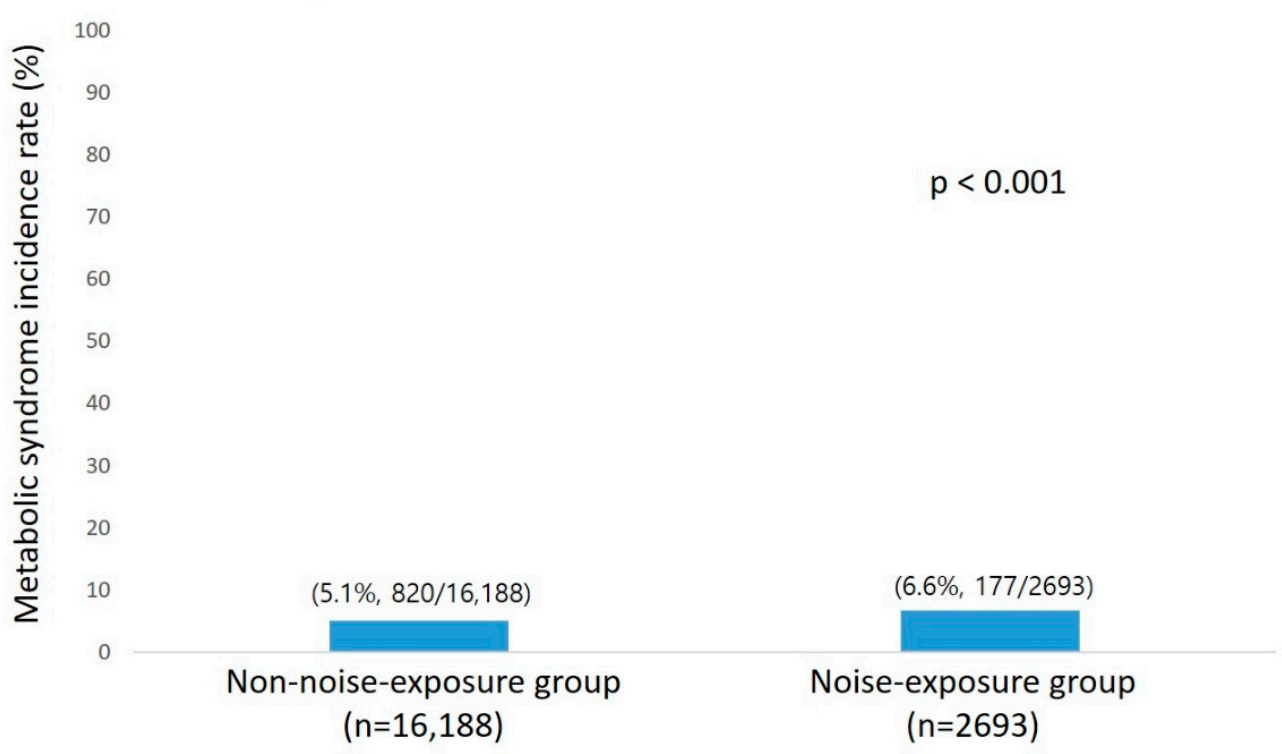

Figure 2. The incidence of metabolic syndrome with or without noise exposure, No. (\%).

3.1.3. Analysis of Risk Factors of Noise Exposure for the Incidence of Metabolic Syndrome

Noise exposure had the crude hazard ratio of 1.48 (95\% CI, 1.32-1.65) in univariate analysis, and the adjusted hazard ratio of 1.36 (95\% CI, 1.19-1.57) in multivariate analysis, which showed it as a statistically significant risk factor of metabolic syndrome (Table 2). The cumulative incidence of metabolic syndrome according to noise exposure during the follow-up period was comparatively analyzed using the Kaplan-Meier plot, and the cumulative incidence of metabolic syndrome was statistically significantly higher in the noise-exposure group $(p<0.001)$ (Figure 3).

Table 2. Effect estimates (and 95\% CIs) from Cox models for noise exposure and the risk of metabolic syndrome for individual component.

\begin{tabular}{ccccc}
\hline \multirow{2}{*}{$\begin{array}{c}\text { Metabolic Syndrome and } \\
\text { Subgroups }\end{array}$} & \multicolumn{2}{c}{ Univariate Model $\mathbf{~}^{\mathbf{1}}$} & \multicolumn{2}{c}{ Adjusted Model $^{\mathbf{2}}$} \\
\cline { 2 - 5 } & HR & $\mathbf{9 5 \%} \mathbf{C I}$ & HR & $\mathbf{9 5 \% ~ C I ~}$ \\
\hline Metabolic syndrome & 1.48 & $(1.32-1.65)$ & 1.36 & $(1.19-1.57)$ \\
Abnormal waist circumference & 0.85 & $(0.70-1.04)$ & 0.97 & $(0.77-1.24)$ \\
Abnormal blood pressure & 1.63 & $(1.47-1.80)$ & 1.18 & $(1.03-1.35)$ \\
Abnormal triglyceride & 1.96 & $(1.79-2.16)$ & 1.52 & $(1.34-1.71)$ \\
Abnormal HDL & 1.13 & $(1.01-1.27)$ & 1.20 & $(1.05-1.39)$ \\
Abnormal glucose & 1.79 & $(1.62-1.97)$ & 1.43 & $(1.26-1.62)$ \\
\hline
\end{tabular}

CI, confidence interval; HR, hazard ratio. ${ }^{1}$ Noise exposure is the only variable. ${ }^{2}$ Adjusted for baseline age gender, smoking history, alcohol habit, physical activity, night-shift work, exposure related to cardiovascular risk. 


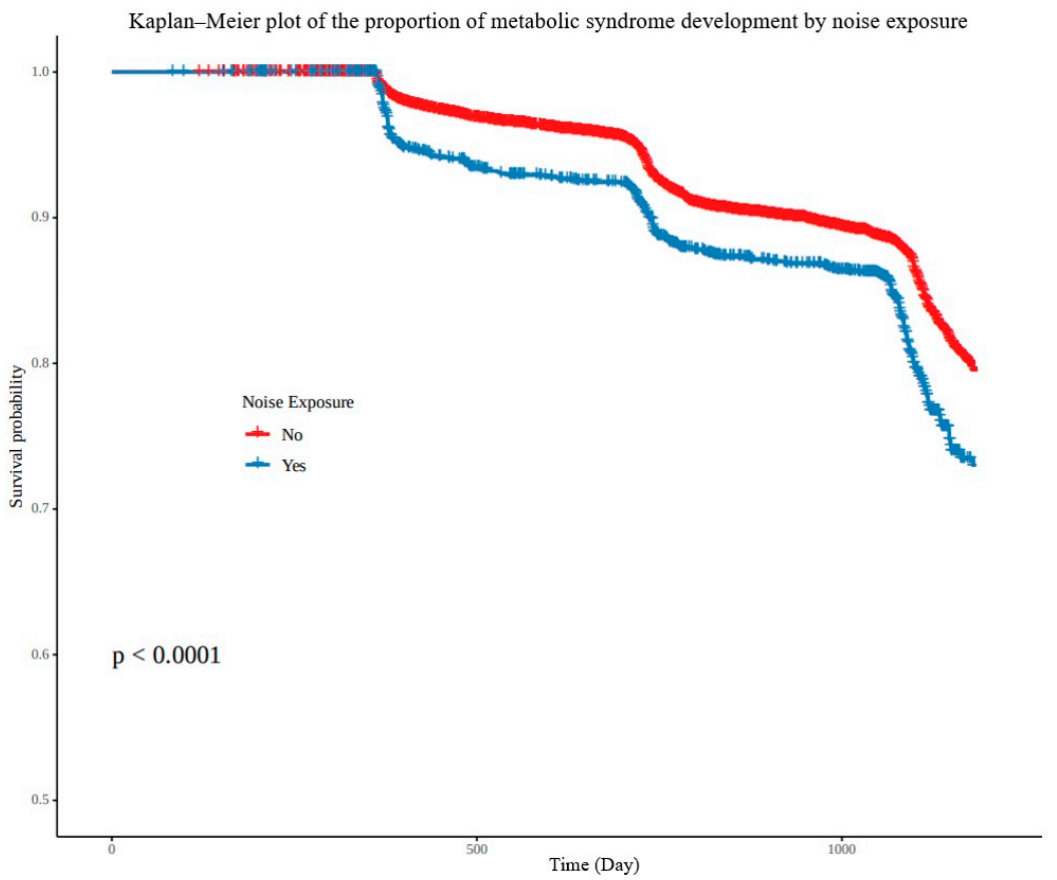

Figure 3. Kaplan-Meier plot of the cumulative incidence of metabolic syndrome with and without noise exposure.

\subsection{Correlation between Noise Exposure and Five Subgroups of Metabolic Syndrome}

In the univariate Cox model, noise exposure was positively correlated with the incidence of four of the five subcategories of metabolic syndrome, and was statistically significant for: elevated blood pressure, elevated TG, lowered HDL-C, and elevated blood sugar. Noise exposure showed a negative correlation with the incidence of abdominal obesity, but was not statistically significant (Table 2). In the multivariate Cox model, sex, age, smoking history, drinking history, physical-activity level, night-shift work, and exposure to cardiovascular risk factors were used as covariates. Even in the multivariate Cox model, noise exposure was a statistically significant risk factor for the incidence of the remaining four subgroups except for abdominal obesity (Table 2).

For noise exposure, the hazard ratios for the occurrence of elevated TG and elevated blood sugar were analyzed as 1.52 (95\% CI, 1.34-1.71) and 1.43 (95\% CI, 1.26-1.62), respectively. The hazard ratios of noise exposure for lowered HDL-C and elevated blood pressure were 1.20 (95\% CI, 1.05-1.39) and 1.18 (95\% CI, 1.03-1.35), respectively (Figure 4). During the follow-up period, the cumulative incidence rates of the five subgroups of metabolic syndrome according to the noise exposure were comparatively analyzed using KaplanMeier plots, and it showed that elevated blood pressure $(p<0.001)$, elevated TG $(p=0.033)$, lowered HDL-C $(p<0.001)$, and elevated blood glucose $(p<0.001)$ in the noise-exposed group were statistically significant. However, no statistical significance was found for abdominal obesity $(p=0.12)$ (Figure 5$)$. 


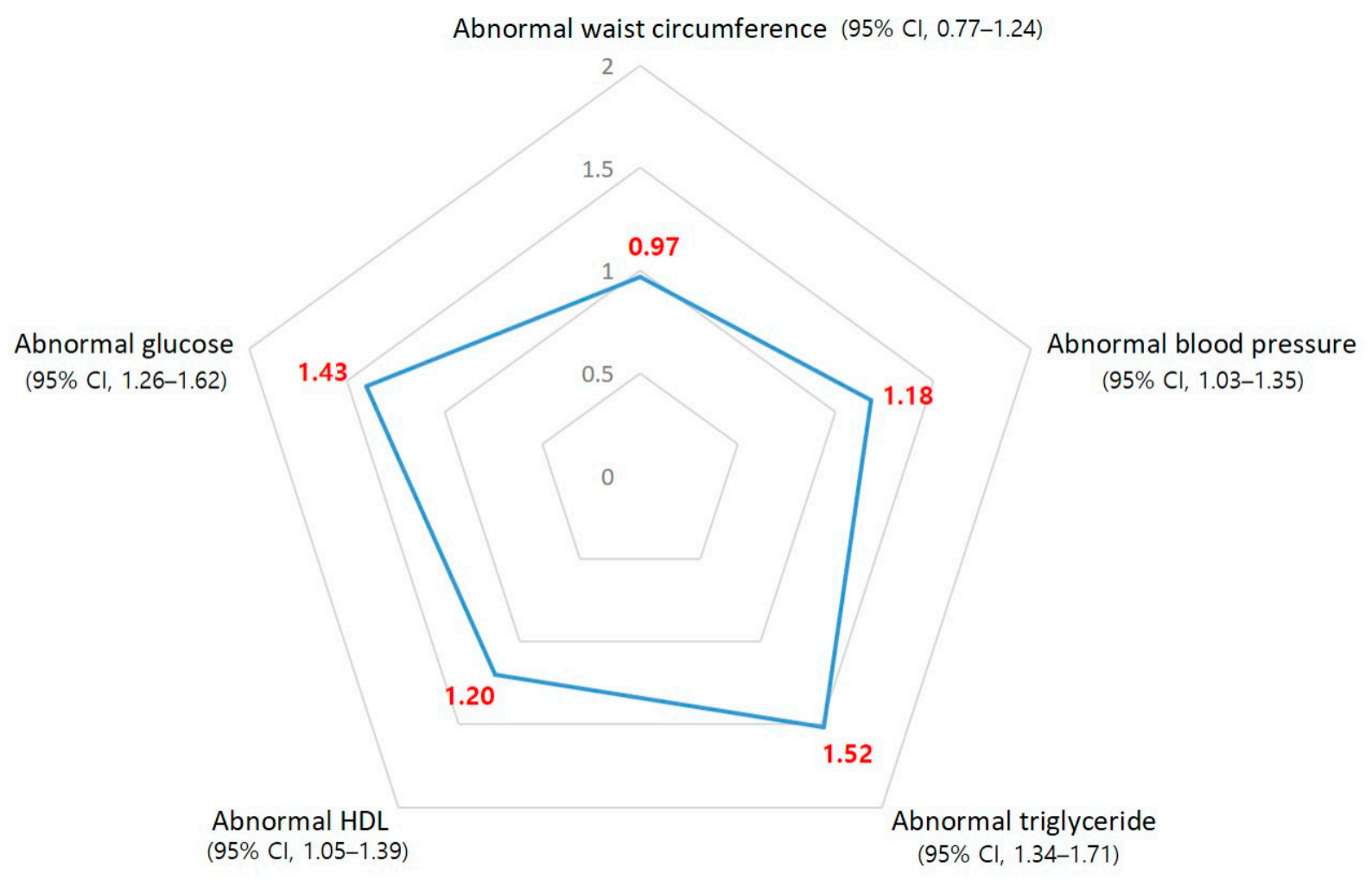

- Hazard ratio

Figure 4. Relative hazard ratio of noise exposure for the incidence of the five subgroups of metabolic syndrome using the adjusted Cox proportional hazard model.

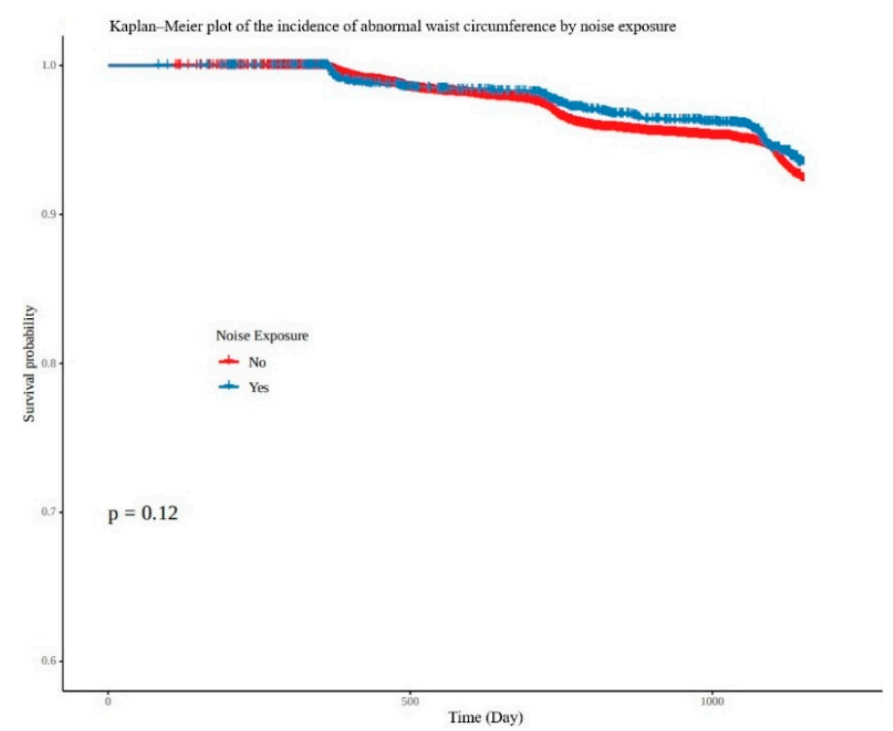

(a)

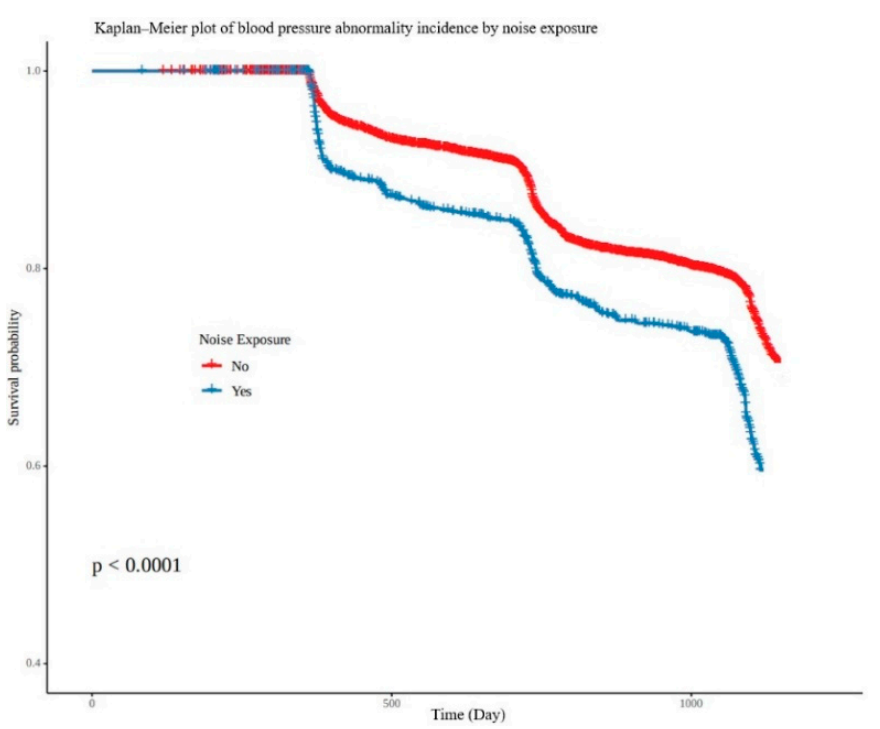

(b)

Figure 5. Cont. 


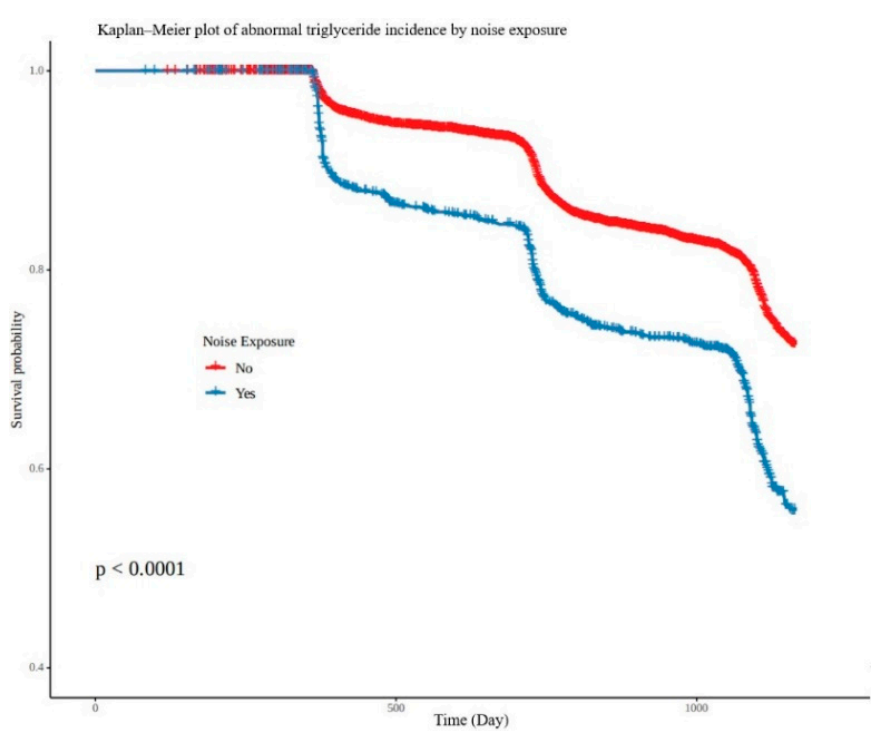

(c)

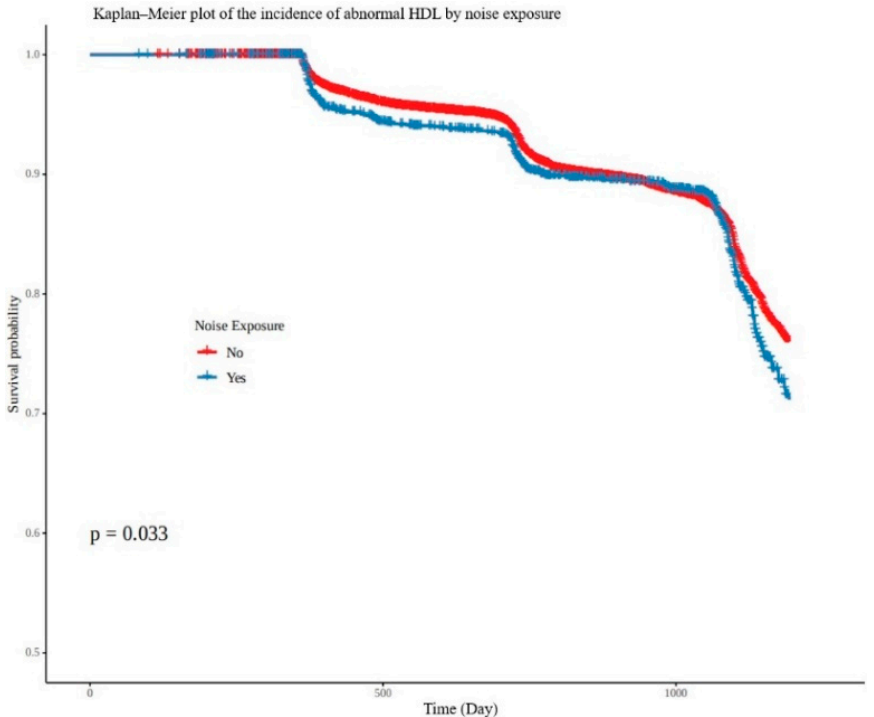

(d)

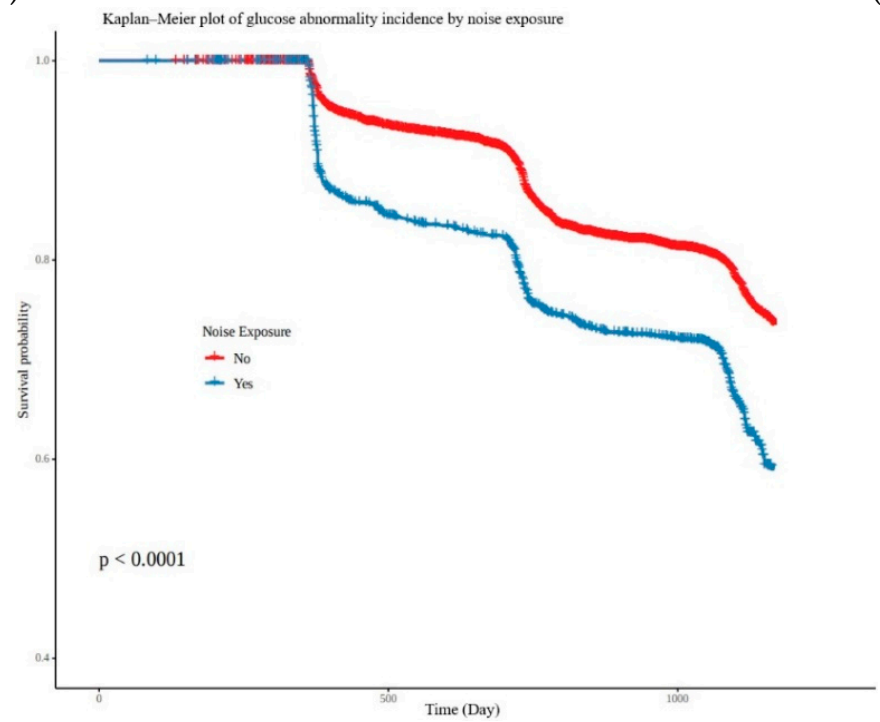

(e)

Figure 5. Kaplan-Meier plot of the incidence of (a) abnormal waist circumference, (b) abnormal blood pressure, (c) abnormal triglyceride, (d) abnormal HDL, (e) abnormal glucose by noise exposure.

\section{Discussion}

In this study conducted with 60,272 workers at one workplace as a study sample, the prevalence of metabolic syndrome was $12.2 \%(7408 / 60,272)$, and during an average followup period of 2.39 years, new cases of metabolic syndrome comprised $5.3 \%(997 / 18,881)$. In the analysis using the multivariate time-dependent Cox proportional hazard model, noise exposure was a statistically significant risk factor for metabolic syndrome with hazard ratio of 1.36 (95\% CI, 1.19-1.57). In particular, it was shown that noise exposure had a statistically significant impact in elevating TG, blood sugar, and blood pressure, and lowering HDL-C among the five subgroups of metabolic syndrome, although there was no statistically significant association with the occurrence of abdominal obesity. Therefore, occupational noise exposure is a significant environmental risk factor for the occurrence of metabolic syndrome.

Although the mechanism of how noise causes metabolic syndrome has not been clearly elucidated, several possible mechanisms exist. Babisch et al. introduced two pathways of how noise affects the body: the direct pathway and the indirect pathway $[22,23]$. The 
direct pathway is activated by the immediate interaction between the auditory nerve and the central nervous system, and the indirect pathway is related to the emotional response as it represents the cognitive recognition of noise and the corresponding activation of the cortex. These two pathways cause activation of the hypothalamic-pituitary-adrenal (HPA) axis and the sympathetic-adrenal-medullary axis, which are involved in the hypothalamus, limbic system, and autonomic nervous system, leading to increase in stress hormone (cortisol, adrenaline, and noradrenaline) levels. It can trigger a variety of bodily responses, also known as stress responses. This stress response can occur through four processes: (1) autonomic nervous system and sympathetic-adrenal-medullary axis activation; (2) release of pro-inflammatory mediators, modified lipids, or phospholipids and activation of leukocyte groups; (3) vascular endothelial dysfunction due to oxidative stress; and (4) activation of the thrombus formation pathway. These pathophysiological pathways can interact with each other and can be activated acutely or chronically at various time points after exposure to noise, and can contribute to the development of metabolic syndrome and cardiovascular disease.

Until now, there have been few papers examining the relationship between noise exposure and metabolic syndrome. Recently, studies in Taiwan and the United States in 2020 covered a similar topic $[11,24]$. The types of noise evaluated in each study are slightly different. A Taiwanese research team studied the relationship between perceived noise and metabolic syndrome in residential areas based on the health examination data of the general public. A US-based research team studied the relationship between traffic-related noise and metabolic syndrome. This was an industrial noise study, different from other studies from Taiwan and the United States.

A Taiwan study by Huang T et al. in 2020 analyzed the health examination data of the general public ( $n=42,509$ people), using the perceived noise-exposure data. They were estimated up to 2003 utilizing data from 2014 and 2015. Consequently, noise exposure was reported as a risk factor for the incidence of metabolic syndrome, and in particular, the higher the noise level, the higher the correlation. Furthermore, in the additional analysis of the five subgroups of metabolic syndrome, noise was significantly associated with hypertriglyceridemia, abdominal obesity, and hyperglycemia, but had no statistical significance for blood pressure and low HDL-C. Although it would be difficult to make a simple comparison because the type of noise studied was not the same, a similar result was reported, namely, that noise exposure is a significant risk factor for the incidence of metabolic syndrome, and noise was found to contribute to hypertriglyceridemia and hyperglycemia among the five subgroups of metabolic syndrome [11]. However, there were differences with our study, which found that noise exposure was also a risk factor for elevated blood pressure and lowered HDL. There may be a difference depending on the type of noise.

In 2020, Yu et al. from the US [24], in a study of Mexican-Americans, targeted 1608 elderly (60 years or older) people to evaluate the effects of traffic-related factors (NOx and noise) on metabolic syndrome. Exposure to traffic-related noise was reported to be associated with the incidence of metabolic syndrome. This result is consistent with that of our study. Regarding the subgroups of metabolic syndrome, noise exposure was associated with hypertension, hyperglycemia, hypertriglyceridemia, and low HDL- C, but there was no statistically significant association with abdominal obesity [24]. This result is consistent with the results of our study.

Yu et al. explained that noise exposure was not related to obesity in their study because the average age of their subjects was 70 years old, an age too late for new obesity to develop during the follow-up period. They also explained that it should be taken into account that the elderly can have a disease that may reduce the abdominal circumference. Their study focused mostly on the elderly, so it is difficult to apply their findings to other age groups.

One of the reasons that noise exposure did not affect abdominal obesity despite the relatively young average age ( 39 years old) of the subjects in our study is that our follow-up period was relatively short. Furthermore, the fact that most of the study subjects had a high 
degree of physical activity may also have attenuated the effect of noise exposure on obesity. In addition, the failure to analyze all the various factors affecting abdominal obesity may also have affected our result.

The strengths of this study included the fairly large sample size, and the target of workers in a single area of industry. Furthermore, there are few studies on the relationship between industrial noise and metabolic syndrome, and it is also meaningful that this is a large cohort study on that point. However, there are several limitations of this study. First, since it is a retrospective study using large-scale screening data, there is a risk of confounding variable and immortal time biases. To overcome this, a multivariate analysis and time-dependent Cox proportional hazards model, and landmark analysis were performed. Second, one of the limitations is that the follow-up period was relatively short, with an average of 2.39 years. A long-term analysis is needed in the future. Third, it was not possible to analyze the data on air pollution and dietary habits as presented in previous papers. However, it is estimated that the exposure to air pollution was relatively similar for the subjects of this study because they worked and lived in a single area, Ulsan city. However, further analysis on this point is required in the future. Fourth, it was not possible to compare each level of noise exposure. Fifth, it was not possible to analyze the data on sitting time, which could affect the occurrence of metabolic syndrome along with noise exposure. However, all participants included here were not white-collar workers, but production workers, therefore, data on sitting time could not be included. Finally, only noise exposure in industrial workplaces was reflected, and noise exposure in residential areas where people spend time after work was not taken into account.

\section{Conclusions}

This study investigated the contribution of occupational noise exposure to the incidence of metabolic syndrome, and in particular, it demonstrated an increase in TG and blood sugar, an elevated blood pressure, and a lowered HDL-C. Managing noise exposure is an important factor in reducing the incidence of metabolic syndrome, although lifestyle factors should also be considered. Further study would be necessary to assure a comprehensive assessment of the impact of noise exposure on metabolic syndrome and subsequent cardiovascular disease risk.

Author Contributions: Conceptualization, G.K., B.Y. and J.L.; methodology, J.S. and B.Y.; software, J.S. and B.Y.; validation, J.Y., B.Y. and J.L.; formal analysis, J.S. and B.Y.; investigation, Y.O., J.Y. and J.L.; resources, J.Y. and J.L.; data curation, C.K., B.Y. and Y.O.; writing-original draft preparation, G.K., H.K. and J.L.; writing-review and editing, J.Y. and J.L.; visualization, B.Y. and G.K.; supervision, J.Y and J.L.; project administration, J.Y and J.L.; funding acquisition, J.L. All authors have read and agreed to the published version of the manuscript.

Funding: This work was supported by the Korea Health Industry Development Institute through "Social and Environmental Risk Research" funded by the Ministry of Health and Welfare (HI19 C0052).

Institutional Review Board Statement: The study was conducted in accordance with the Declaration of Helsinki, and approved by the Institutional Review Board (or Ethics Committee) of Ulsan University Hospital Institutional Review Board (IRB No: 2021-06-042-001).

Informed Consent Statement: Patient consent was waived due to retrospective study, based on the Bioethics and Safety Act.

Data Availability Statement: Data were obtained from health medical examination data from Ulsan University Hospital. Data sharing is not applicable.

Conflicts of Interest: The authors declare no conflict of interest. 


\section{Appendix A}

Table A1. Criteria of metabolic syndrome according to WHO, EGIR, modified NCEP, and IDF definitions.

\begin{tabular}{|c|c|c|c|}
\hline $\begin{array}{c}\text { WHO: } \\
\text { Insulin Resistance } \\
\text { Obligatory + Two Other } \\
\text { Components }\end{array}$ & $\begin{array}{c}\text { EGIR: } \\
\text { Hyperinsulinemia (Plasma } \\
\text { Insulin > 75th Percentile) + } \\
\text { Two Other Components }\end{array}$ & $\begin{array}{l}\text { Modified NCEP: } \\
\text { Three of the Following }\end{array}$ & $\begin{array}{c}\text { IDF: } \\
\text { Waist Obligatory + Two } \\
\text { Other Components }\end{array}$ \\
\hline $\begin{array}{l}\text { Insulin resistance (IGT, IFG, } \\
\text { T2 D) }\end{array}$ & & $\begin{array}{l}\text { Fasting plasma glucose } \geq \\
100 \mathrm{mg} / \mathrm{dL} \text { or treatment for } \\
\text { elevated glucose }\end{array}$ & $\begin{array}{l}\text { Fasting plasma glucose } \geq \\
100 \mathrm{mg} / \mathrm{dL} \text { or treatment for } \\
\text { elevated glucose }\end{array}$ \\
\hline $\begin{array}{c}\text { Waist/hip ratio }>0.9 \text { (men) or } \\
>0.85 \text { (women) or BMI }> \\
30 \mathrm{~kg} / \mathrm{m}^{2}\end{array}$ & $\begin{array}{l}\text { Waist } \geq 94 \mathrm{~cm} \text { (men), or } \\
\quad \geq 80 \mathrm{~cm} \text { (women) }\end{array}$ & $\begin{array}{l}\text { Waist } \geq 102 \mathrm{~cm} \text { (men), or } \\
\quad \geq 88 \mathrm{~cm} \text { (women) }\end{array}$ & $\begin{array}{l}\text { Waist } \geq 94 \mathrm{~cm} \text { (men), or } \\
\quad \geq 80 \mathrm{~cm} \text { (women) }\end{array}$ \\
\hline $\begin{array}{c}\mathrm{TG}>150 \mathrm{mg} / \mathrm{dL} \text { or HDL } \\
\text { cholesterol }<35 \mathrm{mg} / \mathrm{dL} \text { (men) } \\
\text { or }<39 \mathrm{mg} / \mathrm{dL} \text { (women) }\end{array}$ & $\begin{array}{l}\mathrm{TG}>177 \mathrm{mg} / \mathrm{dL} \text { or HDL } \\
\text { cholesterol }<39 \mathrm{mg} / \mathrm{dL}\end{array}$ & $\begin{array}{l}\mathrm{TG}>150 \mathrm{mg} / \mathrm{dL} \text { or } \\
\text { treatment for this lipid } \\
\text { abnormality }\end{array}$ & $\begin{array}{l}\mathrm{TG}>150 \mathrm{mg} / \mathrm{dL} \text { or } \\
\text { treatment for this lipid } \\
\text { abnormality }\end{array}$ \\
\hline Microalbuminuria & & $\begin{array}{c}\text { HDL cholesterol }<40 \mathrm{mg} / \mathrm{dL} \\
\text { (men) or }<50 \mathrm{mg} / \mathrm{dL} \text { (women) } \\
\text { or treatment for this lipid } \\
\text { abnormality }\end{array}$ & $\begin{array}{c}\text { HDL cholesterol }<40 \mathrm{mg} / \mathrm{dL} \\
\text { (men) or }<50 \mathrm{mg} / \mathrm{dL} \text { (women) } \\
\text { or treatment for this lipid } \\
\text { abnormality }\end{array}$ \\
\hline \multirow[t]{2}{*}{$\begin{array}{c}\text { Blood pressure > } \\
140 / 90 \mathrm{mmHg}\end{array}$} & $\begin{array}{c}\text { Blood pressure }> \\
140 / 90 \mathrm{mmHg} \text { or } \\
\text { antihypertensive medication }\end{array}$ & $\begin{array}{c}\text { Blood pressure }> \\
130 / 85 \mathrm{mmHg} \text { or } \\
\text { antihypertensive medication }\end{array}$ & $\begin{array}{c}\text { Blood pressure }> \\
130 / 85 \mathrm{mmHg} \text { or } \\
\text { antihypertensive medication }\end{array}$ \\
\hline & \multicolumn{3}{|c|}{$\begin{array}{l}\text { WHO, World Health Organization; EGIR, European Group for the Study of Insulin Resistance; NCEP, National } \\
\text { Cholesterol Education Program; IDF, International Diabetes Federation; waist, waist circumference; IGT, impaired } \\
\text { glucose tolerance; IFG, impaired fasting glucose; T2 D, type } 2 \text { diabetes; BMI, body mass index; TG, triglycerides, } \\
\text { HDL, high-density lipoprotein; Microalbuminuria, urinary albumin excretion of } \geq 20 \mathrm{ug} / \mathrm{min} \text { or albumin-to- } \\
\text { creatinine ratio of } \geq 30 \mathrm{mg} / \mathrm{g} \text {. }\end{array}$} \\
\hline
\end{tabular}




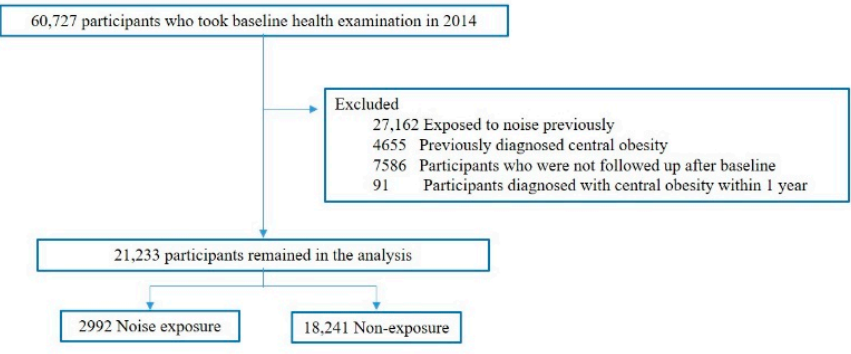

(a)

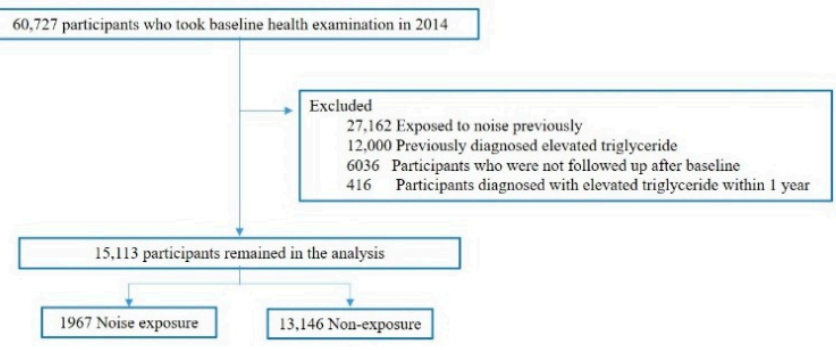

(c)

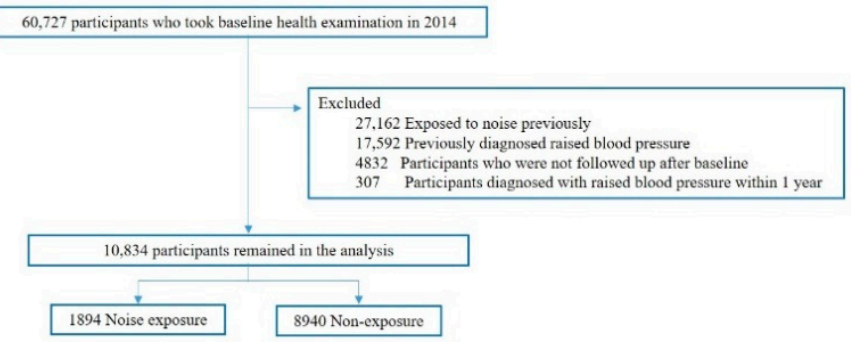

(b)

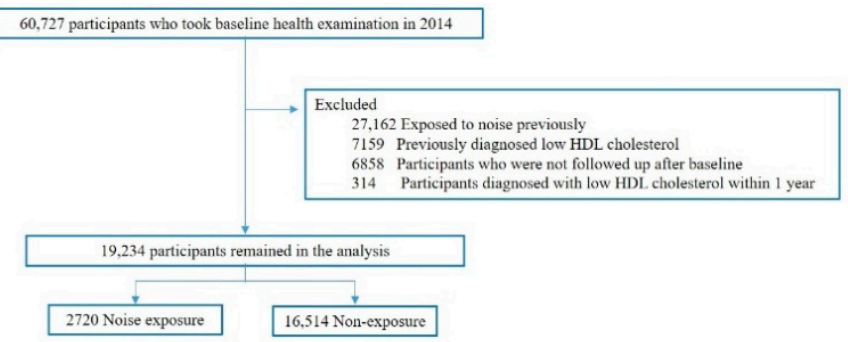

(d)

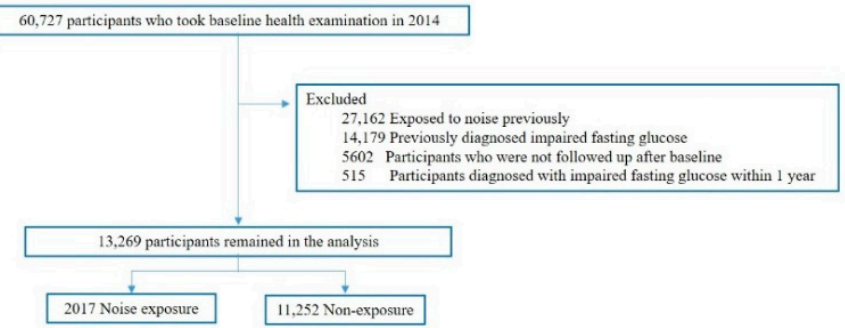

(e)

Figure A1. Algorithm of selecting study subjects for analysis of noise effect on (a) central obesity, (b) elevated blood pressure, (c) elevated triglyceride, (d) low HDL, (e) impaired fasting glucose.

\section{References}

1. Alberti, K.G.; Zimmet, P.Z. Definition, diagnosis and classification of diabetes mellitus and its complications. Part 1: Diagnosis and classification of diabetes mellitus provisional report of a WHO consultation. Diabet. Med. 1998, 15, 539-553. [CrossRef]

2. Huang, P.L. A Comprehensive Definition for Metabolic Syndrome. Dis. Model Mech. 2009, 2, 231-237. [CrossRef]

3. He, Y.N.; Zhao, W.H.; Zhao, L.Y.; Yu, D.M.; Zhang, J.; Yang, X.G.; Ding, G.G. Prevalence of metabolic syndrome in Chinese adults in 2010-2012. Zhonghua Liu Xing Bing Xue Za Zhi = Zhonghua Liuxingbingxue Zazhi 2017, 38, $212-215$.

4. Shin, D.; Kongpakpaisarn, K.; Bohra, C. Trends in the prevalence of metabolic syndrome and its components in the United States 2007-2014. Int. J. Cardiol. 2018, 259, 216-219. [CrossRef]

5. Kim, M.H.; Lee, S.H.; Shin, K.S.; Son, D.Y.; Kim, S.H.; Joe, H.; Yoo, B.W.; Hong, S.H.; Cho, C.Y.; Shin, H.S.; et al. The change of metabolic syndrome prevalence and its risk factors in korean adults for decade. Korea national health and nutrition examination survey for 2008-2017. Korean J. Fam. Pract. 2020, 10, 44-52. [CrossRef]

6. $\quad$ Mendrick, D.L.; Diehl, A.M.; Topor, L.S.; Dietert, R.R.; Will, Y.; La Merrill, M.A.; Bouret, S.; Varma, V.; Hastings, K.L.; Schug, T.T.; et al. Metabolic syndrome and associated diseases: From the bench to the clinic. Toxicol. Sci. 2018, 162, 36-42. [CrossRef]

7. Farooqui, A.A.; Farooqui, T.; Panza, F.; Frisardi, V. Metabolic syndrome as a risk factor for neurological disorders. Cell. Mol. Life Sci. 2012, 69, 741-762. [CrossRef]

8. Baffi, C.W.; Wood, L.; Winnica, D.; Strollo, P.J., Jr.; Gladwin, M.T.; Que, L.G.; Holguin, F. Metabolic syndrome and the lung. Chest 2016, 149, 1525-1534. [CrossRef]

9. Grundy, S.M. Metabolic syndrome update. Trends Cardiovasc. Med. 2016, 26, 364-373. [CrossRef]

10. Stančáková, A.; Laakso, M. Genetics of metabolic syndrome. Rev. Endocr. Metab. Disord. 2014, 15, 243-252. [CrossRef]

11. Huang, T.; Chan, T.-C.; Huang, Y.-J.; Pan, W.-C. The association between noise exposure and metabolic syndrome: A longitudinal cohort study in Taiwan. Int. J. Environ. Res. Public Health 2020, 17, 4236. [CrossRef] [PubMed]

12. Li, W.; Ruan, W.; Yi, G.; Chen, Z.; Wang, D. Association of noise exposure with risk of metabolic syndrome: Evidence from 44,698 individuals. Diabetes Res. Clin. Pract. 2021, 178, 108944. [CrossRef] 
13. Sakhvidi, M.J.Z.; Sakhvidi, F.Z.; Mehrparvar, A.H.; Foraster, M.; Dadvand, P. Association between noise exposure and diabetes: A systematic review and meta-analysis. Environ. Res. 2018, 166, 647-657. [CrossRef]

14. Dzhambov, A.M. Long-term noise exposure and the risk for type 2 diabetes: A meta-analysis. Noise Health 2015, 17, 23. [CrossRef] [PubMed]

15. Bolm-Audorff, U.; Hegewald, J.; Pretzsch, A.; Freiberg, A.; Nienhaus, A.; Seidler, A. Occupational noise and hypertension risk: A systematic review and meta-analysis. Int. J. Environ. Res. Public Health 2020, 17, 6281. [CrossRef] [PubMed]

16. Kheirandish, A.; Mehrparvar, A.; Abou-Bakre, A.; Zare Sakhvidi, M.J. Association between long-term occupational noise exposure and obesity. Environ. Sci. Pollut. Res. 2021, 1-10. [CrossRef]

17. NIOSH Criteria for a Recommended Standard: Occupational Exposure to Heat and Hot Environments. Available online: https:/ /books.google.com.hk/books?hl=zh-CN\&lr=\&id=KxD6HGC86S8C\&oi=fnd\&pg=PR25\&dq=Health,+Control+ $\mathrm{CfD},+$ Prevention, + Dept+HS.+NIOSH+criteria+for+a+recommended+standard:+Occupational+exposure+to+heat+and +hot+ environments:+National+Institute+on+Drug+Abuse\&ots=-4YDagm9Kt\&sig=2HXvSTqmCsXwfo38FxEJbZREH58\&redir_esc= y (accessed on 7 January 2022).

18. Threshold Limit Values for Chemical Substances and Physical Agents and Biological Exposure Indices. Available online: https:/ / www.cdc.gov/niosh/topics/noise/preventhearingloss/hearlosspreventprograms.html (accessed on 7 January 2022).

19. Seo, M.H.; Lee, W.Y.; Kim, S.S.; Kang, J.H.; Kim, K.K.; Kim, B.Y.; Kim, Y.H.; Kim, W.J.; Kim, E.M.; Kim, H.S.; et al. Committee of clinical practice guidelines, Korean society for the study of obesity (KSSO). 2018 Korean society for the study of obesity guideline for the management of obesity in korea. J. Obes. Metab. Syndr. 2019, 28, 40-45. [CrossRef]

20. Korea Centers for Disease Control \& Prevention National Health Information Portal. 2022. Available online: https://health.kdca. go.kr/healthinfo/biz/health/gnrlzHealthInfo/gnrlzHealthInfo/gnrlzHealthInfoView.do (accessed on 7 January 2022).

21. Oh, J.Y.; Yang, Y.J.; Kim, B.S.; Kang, J.H. Validity and reliability of Korean version of International Physical Activity Questionnaire (IPAQ) short form. J. Korean Acad. Fam. Med. 2007, 28, 532-541.

22. Babisch, W. The noise/stress concept, risk assessment and research needs. Noise Health 2002, 4, 1.

23. Babisch, W. Cardiovascular effects of noise. Noise Health 2011, 13, 201. [CrossRef]

24. Yu, Y.; Paul, K.; Arah, O.A.; Mayeda, E.R.; Wu, J.; Lee, E.; Shih, I.F.; Su, J.; Jerrett, M.; Haan, M.; et al. Air pollution, noise exposure, and metabolic syndrome-A cohort study in elderly Mexican-Americans in Sacramento area. Environ. Int. 2020, 134, 105269. [CrossRef] [PubMed] 